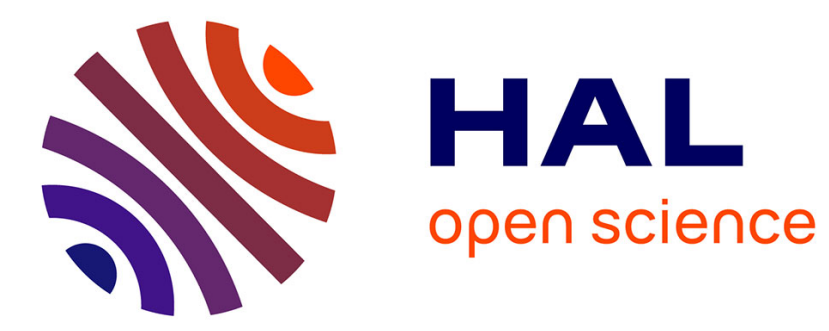

\title{
Realization of a Smart Electrolytic Capacitor Circuit
}

Pascal Venet, Frédéric Perisse, M. H. El-Husseini, Gérard Rojat

\section{To cite this version:}

Pascal Venet, Frédéric Perisse, M. H. El-Husseini, Gérard Rojat. Realization of a Smart Electrolytic Capacitor Circuit. IEEE Industry Applications Magazine, 2002, 8 (1), pp.16-20. hal-00258132

\section{HAL Id: hal-00258132 \\ https://hal.science/hal-00258132}

Submitted on 21 Feb 2008

HAL is a multi-disciplinary open access archive for the deposit and dissemination of scientific research documents, whether they are published or not. The documents may come from teaching and research institutions in France or abroad, or from public or private research centers.
L'archive ouverte pluridisciplinaire HAL, est destinée au dépôt et à la diffusion de documents scientifiques de niveau recherche, publiés ou non, émanant des établissements d'enseignement et de recherche français ou étrangers, des laboratoires publics ou privés. 


\section{Realization of a Smart}
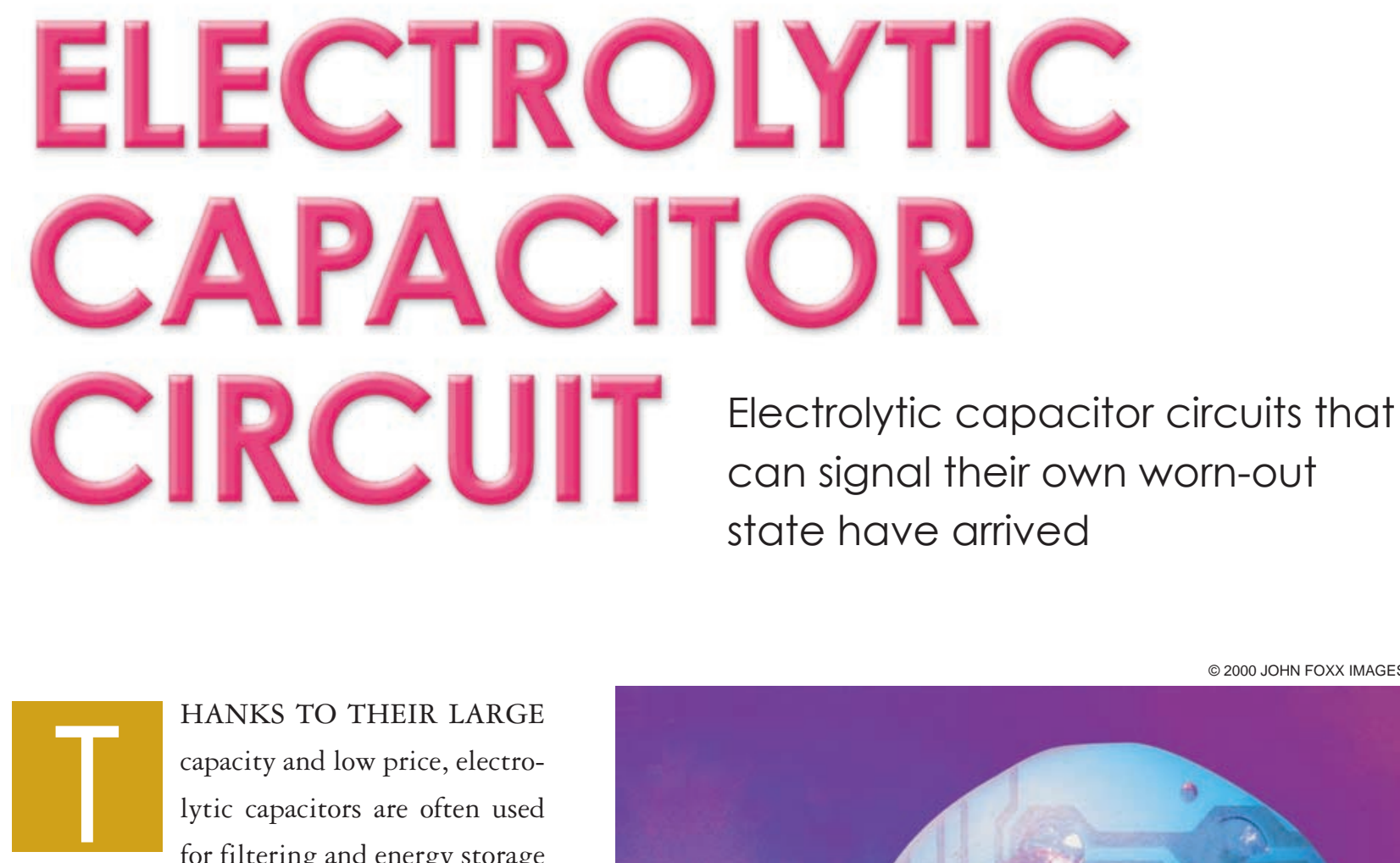

HANKS TO THEIR LARGE

capacity and low price, electrolytic capacitors are often used for filtering and energy storage applications. The major disadvantage of these components is their low reliability. Software and electronic modules have been developed to compute the lifetime of electrolytic capacitors online [1]-[3], but these monitoring systems haves three main drawbacks:

a They are rather expensive.

- They depend on the static converter structure.

- They cannot predict the fault of one capacitor if several capacitors are in parallel.

The object of this article is to present an economic electronic module integrated on an electrolytic capacitor that is able to indicate the moment when it must be changed. First, with a switchmode power supply as an example, the high probability of electrolytic capacitor failure with respect to other power components is BY P. VENET, F. PERISSE, M.H. EL-HUSSEINI, \& G. ROJAT 
noted. Second, we recall that the increase of the equivalent series resistance (ESR) of the capacitor is the best indicator of their faulty state. From the measurements of the voltage ripple and the capacitor current, we can deduce the ESR; the latter is compared to the ESR value of the sound capacitor deduced from the component case temperature. Thus, the capacitor deterioration can be diagnosed.

\section{Parameter Identification of Electrolytic Capacitors}

\section{Presentation of the Capacitors}

The capacitors used in this study are aluminum electrolytic capacitors rated $2,200 \mu \mathrm{F}, 10 \mathrm{~V}, 105^{\circ} \mathrm{C}$. They are used in a $\mathrm{dc} / \mathrm{dc}$ "forward" type converter running at $66 \mathrm{kHz}$ to filter the output voltage (Fig. 1).

Referring to MIL-HDBK $217 \mathrm{~F}$ standard [4], we present (Fig. 2) the failures distribution of each power component at ambient temperature $\left(T_{A}\right)$ of $25^{\circ} \mathrm{C}$ and under rated conditions. We also note the high failure probability of aluminum electrolytic capacitors.

\section{Characterization of Capacitors}

A capacitor can be represented by the simplified equivalent circuit of Fig. 3, where:

- $C$ is the capacitance.

- ESR represents all ohmic circuit losses in the capacitor.

- The equivalent series inductance (ESL) depends on the number of the supply lines to the electrodes and the winding construction.

These parameters depend on frequency and temperature.

The impedance of the simplified circuit is given by

$$
Z=\sqrt{\mathrm{ESR}^{2}+\left(\mathrm{ESL} \cdot \omega-\frac{1}{C \omega}\right)^{2}}
$$

The variations of $Z$ and ESR versus frequency at $25^{\circ} \mathrm{C}$ are shown in Fig. 4.

At frequencies above $10 \mathrm{kHz}, 1 /(C \omega)$ and ESL $\omega$ can be neglected compared to ESR; thus, ESR is the predominant factor in the capacitor's impedance.

ESR varies with the temperature, and this effect is modeled by (2) [5].

$$
\mathrm{ESR}=\alpha+\beta \cdot e^{-\frac{T_{C_{0}}}{\delta}},
$$

where $T_{C_{0}}$ is the capacitor core temperature in Kelvin, and $\alpha, \beta$, and $\delta$ depend on the capacitor type.

The value of ESR versus the core temperature for a 2,200 $\mu \mathrm{F}, 10 \mathrm{~V}, 105^{\circ} \mathrm{C}$ sound capacitor at $66 \mathrm{kHz}$ is shown in Fig. 5. To measure ESR, an inductance-capacitance-resistance (LCR) meter (HP 4284A) injecting a low current ripple through the capacitor is used. $T_{C_{0}}$ can be assimilated to the case temperature $\left(T_{C a}\right)$ and $T_{A}$ because self-heating can be neglected. So $\alpha, \beta$, and $\delta$ can be found experimentally by least squares fit. For the capacitors considered $\alpha=19,5 \mathrm{~m} \Omega, \beta=2$, $63 \cdot 10^{9} \mathrm{~m} \Omega$, and $\delta=16,23$ with ESR in $\mathrm{m} \Omega$ and $T_{C_{o}}$ in Kelvin. The law deduced from this model is shown in Fig. 5.

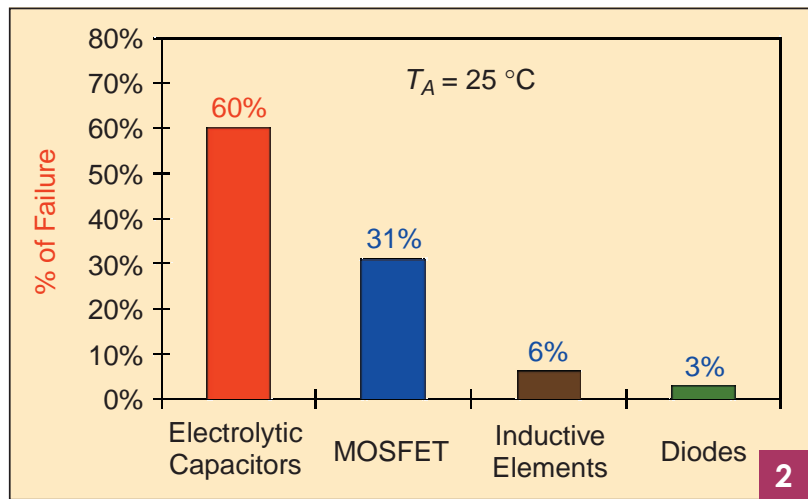

Failures distribution per power component.

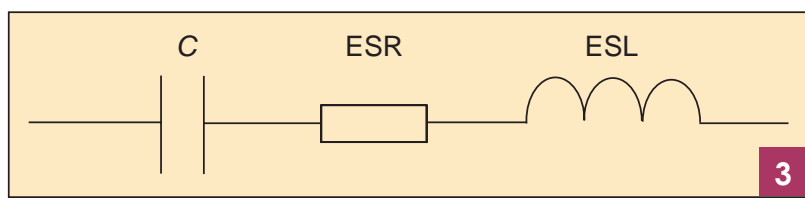

Simplified equivalent circuit of a capacitor.

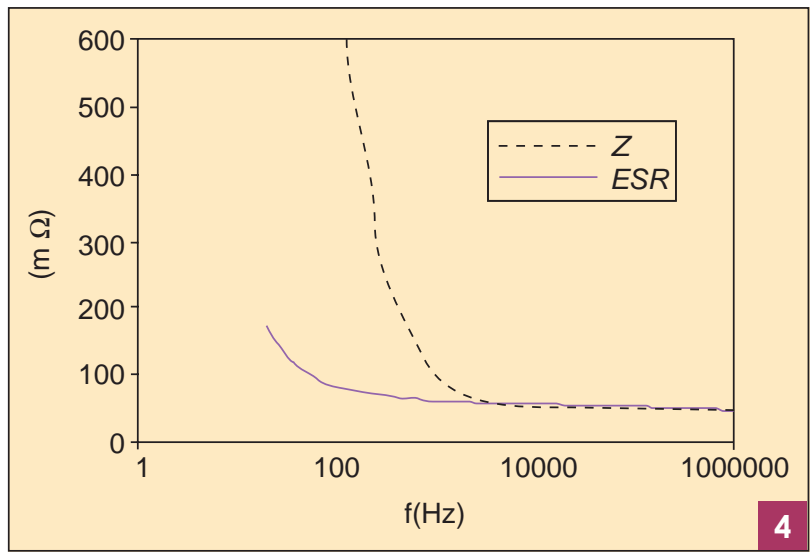

$\mathrm{Z}$ and ESR variations versus frequency at $25^{\circ} \mathrm{C}$.

\section{Influence of the Current Ripple through the Capacitor}

During the operation of a converter, the current ripple flowing through the capacitor raises $T_{C_{0}}$.

A simple thermal model of a capacitor consists of two thermal resistors in series, one from core to case $\left(R t h_{C o C a}\right)$ and the second from case to air $\left(R t h_{C a A}\right)[6]$. Thus, temperature $T_{C_{0}}$ is equal to the sum of $T_{A}$ and a temperature rise given by a function of the thermal resistances and the power losses $P$ such as 


$$
T_{C o}=P \cdot\left(R_{t h} h_{C O C a}+R t h_{C a A}\right)+T_{A}
$$

The core temperature is very important in predicting the life of the capacitor [5], [7]-[10].

The resistance from case to air is the largest contributor to the total thermal resistance from core to air [5], [9]. Therefore, a first approximation may be used by neglecting $R t h C_{C O C a}$ compared to $R t_{C a A}$. As a result, since it is easy to

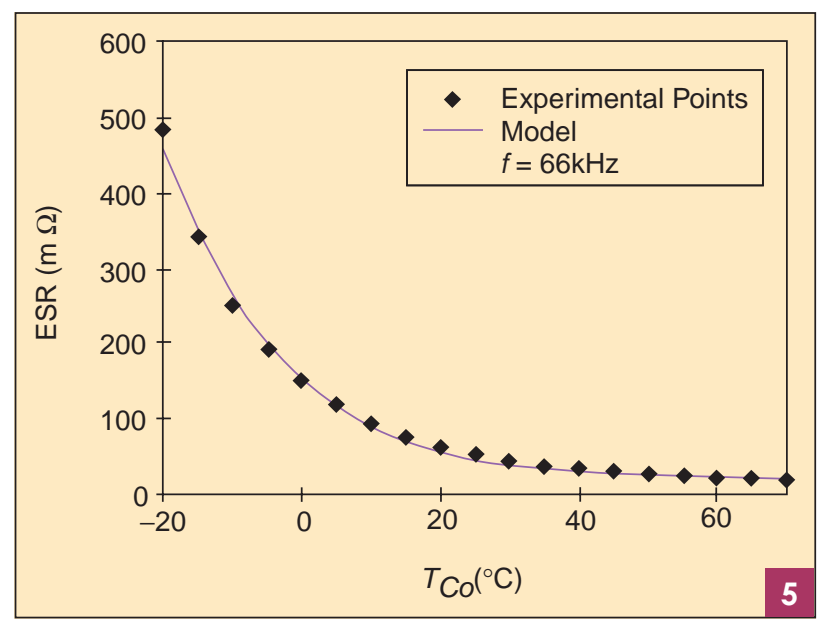

ESR versus $T_{\text {Co }}$ for $2200 \mu \mathrm{F}, 10 \mathrm{~V}, 105^{\circ} \mathrm{C}$ capacitor.

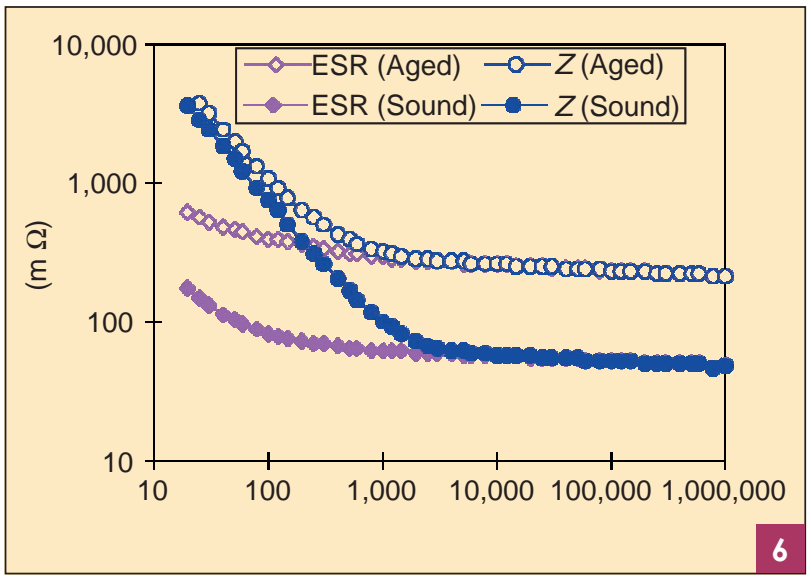

ESR and $Z$ variation versus frequency for sound and aged capacitors at $25^{\circ} \mathrm{C}$.

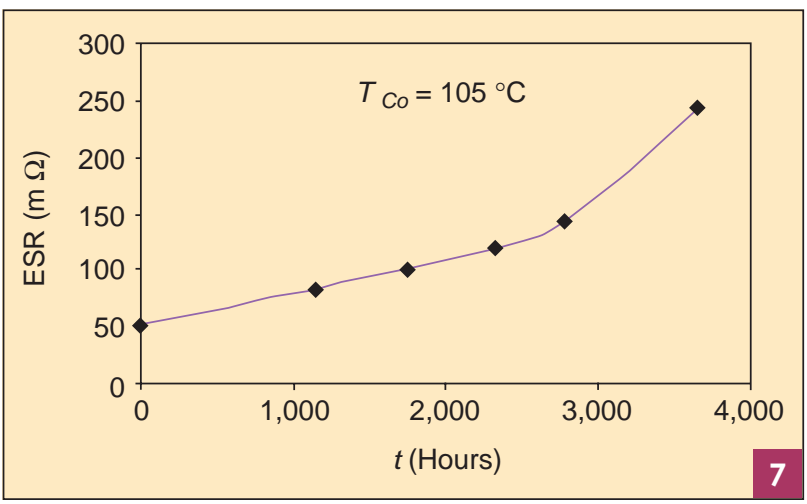

ESR versus aging time at $105^{\circ} \mathrm{C}$. measure $T_{C a}$, we can consider that $T_{C a}$ is similar to $T_{C_{0}}$. As shown previously (2), ESR can be written easily as follows:

$$
\mathrm{ESR}=\alpha+\beta \cdot e^{-\frac{T_{C a}}{\delta}} .
$$

Greater accuracy could be obtained by considering thermal models [8]-[10] or by introducing a temperature sensor on the aluminum terminal tabs of the capacitor.

\section{Influence of the Wearing-Out}

The wear-out of aluminum electrolytic capacitors is due to the vaporization of electrolytes that leads to an increase of ESR and a decrease of $C[5]-\{7],[11],[12]$. To observe this evolution, we applied an accelerated thermal aging at 105 ${ }^{\circ} \mathrm{C}$ and $10 \mathrm{~V}$ to 50 capacitors rated $2,200 \mu \mathrm{F}, 10 \mathrm{~V}$ and 105 ${ }^{\circ} \mathrm{C}$. In Fig. 6, we represent the effects of this test upon ESR and $Z$ measured at $25^{\circ} \mathrm{C}$ versus frequency for sound and aged capacitors (aging time $t=3650$ hours).

This figure confirms that, at frequencies above $10 \mathrm{kHz}$ for sound and aged capacitors, $Z$ is almost equal to ESR.

A foretelling sign of failure could, therefore, be the rise of the ESR, which can increase at a ratio greater than 2, this increase being more rapid toward the end of the life of the capacitor [1]-[3], [11]-[13]. The experimental values of the ESR measured at $66 \mathrm{kHz}$ and at $T_{A}=25^{\circ} \mathrm{C}$ and for the aging test at $105^{\circ} \mathrm{C}$ are shown in Fig. 7 .

During static converter operation, the only modified waveform when the ESR value increases is the voltage ripple $\Delta v_{C}$ across the capacitor. It is linked to the capacitor impedance $Z$ by the relation

$$
\Delta v_{C}=Z \cdot \Delta i_{C}
$$

where $\Delta i_{C}$ is the current ripple through the capacitor [3], [13].

\section{Electrolytic-Capacitor Monitoring Method}

As static converters work most of the time at variable load, high transient values of the voltage ripple $\Delta v_{C}$ occur at the moment of load change and may lead to incorrectly predicted service lives of the capacitor. To avoid these transient values, the fundamental component of $\Delta v_{C}$ is extracted. This waveform gives a very faithful image of

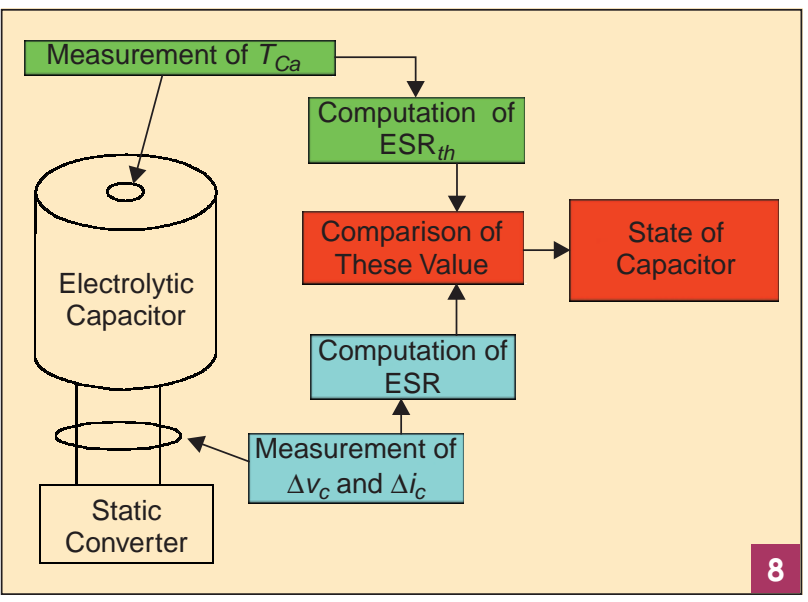

Capacitor monitoring principle. 


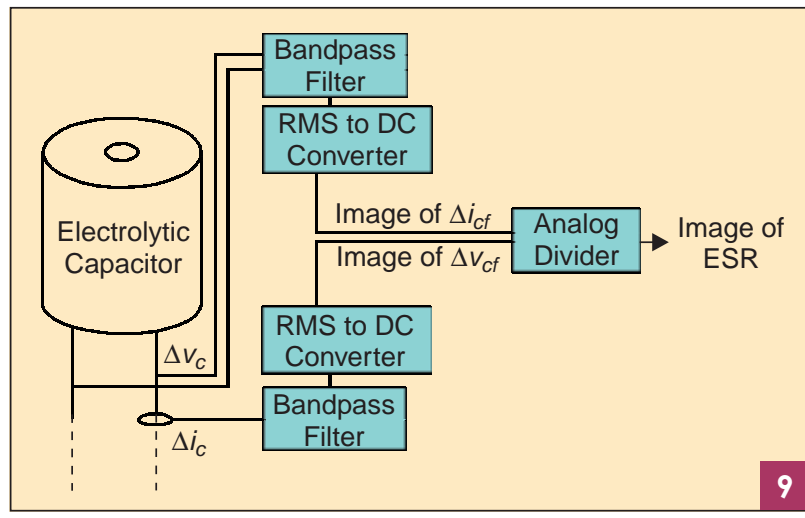

Computation circuit of ESR.

ESR [1]-[3]. Thus, (5) applied to the fundamental components of $\Delta v_{C}$ and $\Delta i_{C}$, denoted, respectively, by $\Delta v_{C f}$ and $\Delta i_{C f}$, gives the next relation:

$$
\Delta v_{C f}=Z \cdot \Delta i_{C f} .
$$

Since $Z$ is approximately equal to ESR at frequencies above $10 \mathrm{kHz}$, ESR can be deduced online during capacitor operation. The equation of ESR is given by

$$
\mathrm{ESR} \approx \frac{\Delta v_{C f}}{\Delta i_{C f}} .
$$

The value of the theoretical equivalent series resistance $\left(\mathrm{ESR}_{t h}\right)$ for a sound capacitor is obtained thanks to (4). The comparison of this latter with the measured ESR gives the state of the capacitor.

The electronic circuit, which allows us to monitor the capacitor, includes three parts [14]

- Computation of ESR, thanks to the measures of $\Delta v_{C}$ and $\Delta i_{C}$

- Computation of $\mathrm{ESR}_{t h}$, thanks to the measure of $T_{C}$

- Comparison of ESR and $\mathrm{ESR}_{t h}$.

The capacitor monitoring principle is given in Fig. 8.

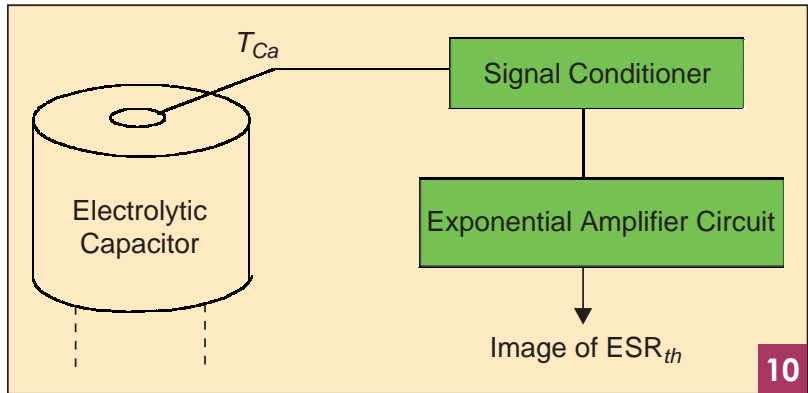

Computation circuit of $\mathrm{ESR}_{\mathrm{th}}$.

\section{Electronic Circuit}

\section{Computation of ESR}

The true value of ESR is deduced from (7).

The current ripple $\Delta i_{C}$ through the capacitor is measured thanks to toroidal core. Then, an image of the fundamental component $\Delta i_{C f}$ of $\Delta i_{C}$ is obtained, thanks to a bandpass filter and a rms to dc converter.

In the same way, we can get an image of the fundamental component $\Delta v_{C f}$.

The division of $\Delta v_{C f}$ and $\Delta i_{C f}$ is realized with an analog divider.

The computation circuit of ESR is shown in Fig. 9.

\section{Computation of $\mathrm{ESR}_{\text {th }}$}

The value of ESR for a sound capacitor is computed from the measure of $T_{c}$ and from (4), thanks to a signal conditioner and an exponential amplifier circuit (Fig. 10).

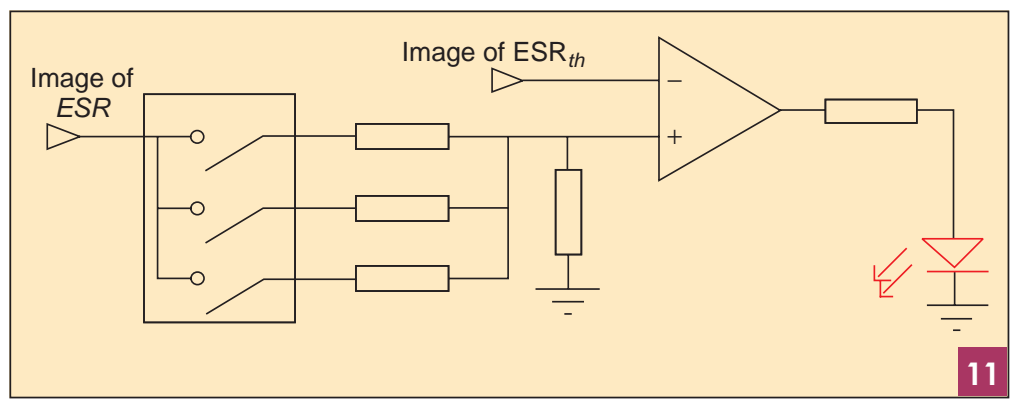

Comparison circuit of ESR and $\mathrm{ESR}_{\mathrm{th}}$.

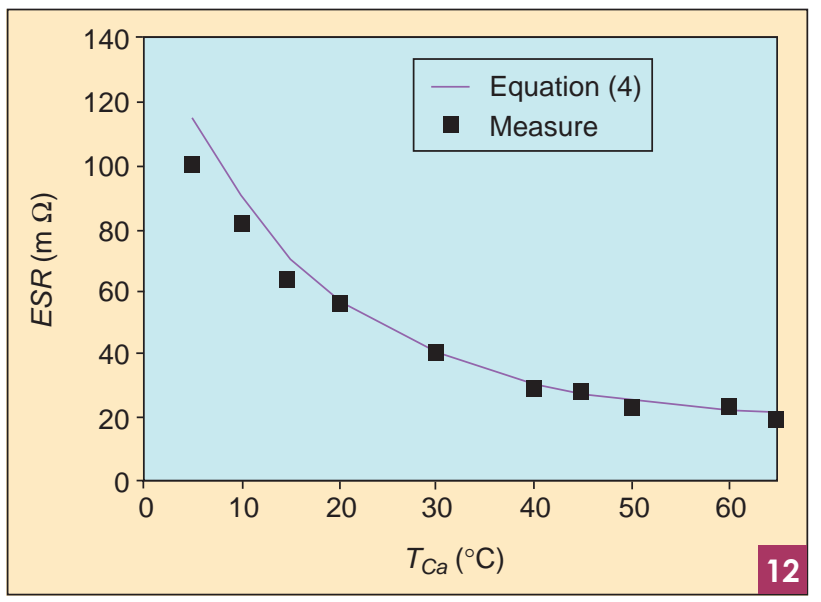

Measured ESR th $_{\text {th }}$ versus $T_{C a}$ compared to (4).

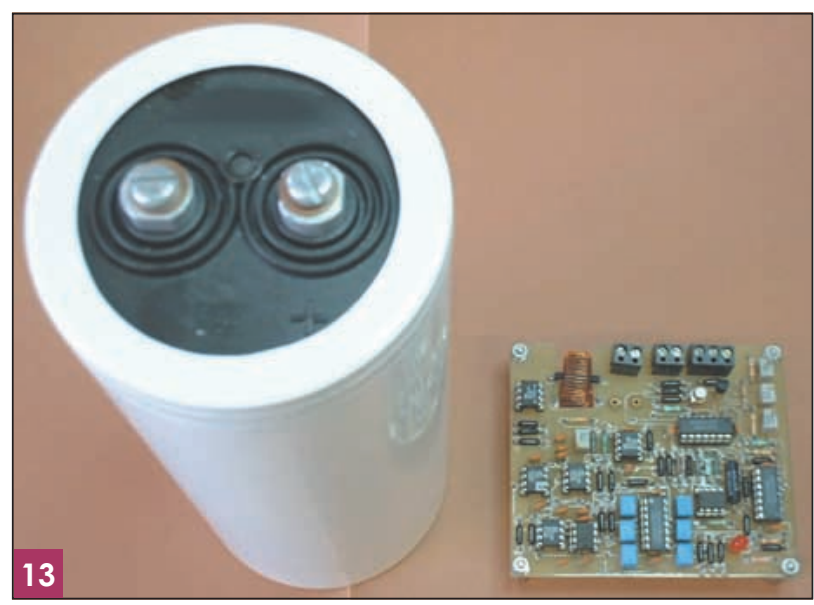

Prototype of the electronic circuit. 


\section{Comparison of ESR and $\mathrm{ESR}_{\text {th }}$}

A comparator makes the comparison of ESR at time $t$ and ESR for a sound capacitor $\left(\mathrm{ESR}_{t h}\right)$. The user can define the limit of the correct running of the capacitor by selecting switches, each of them corresponding to a given increase of initial ESR. A light-emitting diode indicates as soon as ESR has exceeded this limit. The circuit of comparison of ESR and $\mathrm{ESR}_{t h}$ is represented in Fig. 11.

For power supplies, as ESR is almost proportional to $\Delta v_{C}$, the limit of ESR is similar to the limit of $\Delta v_{C}[13]$.

\section{Results}

\section{Computation of ESR}

In order to verify the accuracy of the circuit, we have compared the measures of the image of ESR given by the output of the analog divider to the measures made by the LCR meter. The error of ESR is of a very small percentage.

\section{Computation of $\mathrm{ESR}_{\text {th }}$}

The same method has been applied to $\mathrm{ESR}_{t b}$. The values of this latter are given by the output of the exponential amplifier circuit. Fig. 12 shows the differences between the measured and calculated values with (4) versus $T_{C a}$. The mean difference is less than $10 \%$.

\section{Total Circuit}

The total accuracy of the circuit is roughly $10 \%$, but, due to the shape of $\operatorname{ESR}(t)$ (Fig. 7), the fault detection error is small. Test results mostly agree with the predictions, which allows the assumption that the proposed system is reliable. A prototype of the electronic circuit and is shown in Fig. 13.

\section{Summary}

A smart electrolytic capacitor circuit that is able to signal its worn-out state online has been studied and realized. As the impedance is almost equal to the equivalent series resistance above $10 \mathrm{kHz}$, this smart capacitor circuit can be used in most power supplies. For a static converter operating below $10 \mathrm{kHz}$, active diagnostics consisting of a voltage injection above $10 \mathrm{kHz}$ could be used. This low-price system may be extended to large capacitors and may be subject to circuit integration.

\section{References}

[1] A. Lahyani, P. Venet, G. Grellet, and P.J. Viverge, "Failure prediction of electrolytic capacitors during operation of a switchmode power supply," IEEE Trans. Power Electron., vol. 13, pp. 1199-1207, Nov. 1998.

[2] P. Venet, A. Lahyani, G. Grellet, and A. Ah-Jaco, "Influence of aging on electrolytic capacitors function in static converters: Fault prediction method," Eur. Phys. J. Appl. Phys., no. 5, pp. 71-83, 1999.

[3] A. Lahyani, "Surveillance et diagnostic d'état des condensateurs électrolytiques dans les convertisseurs statiques," Ph.D. dissertation, Claude Bernard Univ., Lyon, 1998.

[4] Reliability Prediction of Electronic Equipment, Military Handbook 217 F, 1995.

[5] M.L. Gasperi, "Life prediction model for aluminum electrolytic capacitors" in Conf. Rec. IEEE 1996 IAS Annu. Meeting, vol. 3, pp. 1347-1351.

[6] B. Alvsten, "Electrolytic capacitors theory and application," RIFA Electrolytic Capacitors, Sweden, 1995.

[7] M.L. Gasperi, "A method for predicting the expected life of bus capacitors," in Conf. Rec. IEEE 1997 IAS Annu. Meeting, vol. 2, pp. 1142-1147.

[8] F.G. Hayatee, "Heat dissipation and ripple current rating in electrolytic capacitors," Electrocomponent Sci. Tech., vol. 2, pp. 109-114, 1975.

[9] L.L. Macomber, "Compute thermal resistance-The key to computer-grade capacitor ripple,” Elec. Des., pp. 80-83, Jun. 7, 1979.

[10] J.L. Stevens, J.D. Sauer, and J.S. Shaffer "Improved thermal model for large can aluminum electrolytic capacitors : An empirical approach," in 15th Capacitor and Resistor Technology Symp. Proc., 1995, pp. 56-61.

[11] G.E. Rhoades and A.W.H. Smith, "Expected life of capacitors with non-solid electrolyte," in 34th Component Conf. Proc., 1984, pp. 156-161.

[12] J.A. Jones and J.A. Hayes "The parametric drift behaviour of aluminium electrolytic capacitors: An evaluation of four models," in 1st European Capacitor and Resistor Tech. Proc., 1987, pp. 171-179.

[13] P. Venet, "Surveillance d'alimentation à découpage. Application à la maintenance prédictive," Ph.D. dissertation, Claude Bernard University, Lyon, 1993.

[14] P. Venet, F. Perisse, G. Grellet, and G. Rojat, "Condensateur intelligent," Patent PCT/FR 00/02 215, 2000.

P. Venet (venet@cegely.univ-lyon1.fr), F. Perisse, M.H. El-Husseini, and G. Rojat are with the Université Claude Bernard de Lyon in Villeurbanne, France. This article first appeared in its original format at the 1999 IEEE International Symposium on Diagnostics for Electrical Machines, Power Electronics and Drives. 